Jurnal Ilmu Keolahragaan Volume II Nomor 1 April 2019

Faisal Idrus

Tersedia di: http://jurnal.untan.ac.id/index.php/jilo

\title{
IMPLEMENTASI METODE TEACHING GAME FOR UNDERSTANDING TERHADAP KEMAMPUAN SHOOTING SEPAKBOLA
}

\author{
Faisal Idrus, \\ Program Studi Pendidikan Kepelatihan Olahraga FKIP Untan Pontianak \\ Email: faisalidrus69@gmail.com
}

\begin{abstract}
Abstrak
Sepakbola merupakan olahraga yang banyak sekali memerlukan keterampilan teknik dasar. Salah satu teknik dasar yang diperlukan ialah tendangan shooting. Tendangan shooting adalah memasukan bola ke gawang dengan cara ditendang untuk mendapatkan sebuah poin. Akan tetapi, banyak pemain yang masih kurang baik dalam melakukan shooting sehingga ketika melakukan penetrasi bola ke gawang kurang efektif. Untuk itu maka dibutuhkan latihan yang terarah dan tepat yaitu dengan menggunakan metode teaching game for understanding (TGfU). Metode penelitian ini menggunakan metode eksperimen dengan rancangan bentuk pre-expremintal design. Subjek penelitian ini adalah pemain Klub PSPI Pontianak. Pengumpulan data menggunakan tes GPAI. Analisis data menggunakan perhitungan statistik uji Wilcoxon, sebelumnya telah diuji normalitas dan homogenitas terlebih dahulu. Metode latihan permainan TGfU dengan hasil shooting didapat nilai signifikansi $0,004<0,05$, jadi metode TGfU dapat meningkatkan kemampuan shooting sepakbola.
\end{abstract}

Kata kunci: Latihan, Shooting Sepakbola, Teaching Game for Understanding (TGfU) 


\section{Jurnal Ilmu Keolahragaan Volume II Nomor 1 April 2019 Faisal Idrus \\ Tersedia di: http://jurnal.untan.ac.id/index.php/jilo}

\section{PENDAHULUAN}

Sepakbola adalah olahraga yang menggunakan bola yang terbuat dari bahan kulit dan dimainkan oleh dua tim yang masing-masing beranggotakan 11 (sebelas) orang pemain inti dan sebagian pemain cadangan (Istofian dan Amiq, 2016). Sepak bola adalah permainan bola yang dimainkan oleh dua tim dengan masing-masing beranggotakan sebelas orang (Al-Hadiqie, 2013). Lapangan yang yang dipakai dalam permainan sepak bola, adalah sebuah lapangan yang luas berbentuk persegi panjang dengan ukuran panjang $100 \mathrm{~m}-$ $110 \mathrm{~m}$ dan lebar $64 \mathrm{~m}$ - 75m (Fadillah, 2009). Durasi di dalam permainan sepak bola yaitu 2 X45 menit.

Kebanyakan orang menganggap bahwa bermain sepakbola adalah olahraga yang mudah dimainkan. Akan tetapi pada kenyataannya bermain sepakbola itu sulit, karena banyak teknik-teknik dasar yang harus dikuasai dengan baik oleh setiap pemain sepakbola (Istofian dan Amiq, 2016). Tidak hanya itu permainan sepak bola juga harus memiliki teknik dasar untuk bisa memainkan bola, salah satunya ialah teknik dalam menendang.

Beberapa teknik dasar sepakbola yang harus dikuasai oleh pemain sepakbola untuk dapat bermain dengan baik adalah pasing, kontrol, menggiring bola, tandukan, menendangan, dan menangkap. Dari semua teknik dasar yang ada dalam sepak bola, teknik menendang bola (shooting) memiliki peran penting dalam sepakbola sesuai dengan tujuan bermain sepakbola (Istofian dan Amiq, 2016). Ferdinansyah dan Abitur (2008) macam-macam teknik menendang ada 3 yaitu: menendang dengan kaki bagian luar, menendang kaki dengan bagian dalam dan, menendang dengan pungung kaki. Menendang merupakan teknik dasar yang harus dikuasai oleh pemain tanpa melakukan tendangan yang baik maka tidak akan menjalankan permainan yang bagus dan menghasilkan poin. Ada 2 teknik dalam menendang bola yang peratama adalah dengan menendang passsing dan shooting kegawang lawan.
Tendangan passing digunakan untuk memberikan atau mengoper bola ke team sendiri, sedangkan shooting merupakan suatu usaha tendangan dengan menggunakan bola yang arahnya menuju gawang lawan. Shooting menembak bola cukup menendang bola keras-keras ke arah gawang (Bianca, 2010) Shooting merupakan salah satu teknik dasar yang harus mendapatkan perhatian yang ektra dari pelatih yang mengajarkan sepak bola karena penentuan kemenangan adalah dari tendangan langsung ke gawang lawan, dan untuk mendapatkan hasil yang maksimal pemain harus memilki kemampuan motorik yang tinggi sehingga memiliki kemampuan power yang tinggi untuk dapat menghasilkan tendangan tepat kegawang lawan (Dewi dan Sitompul, 2016). Salah satu kemampuan dasar yang sangat penting dikuasai oleh pemain ialah kemampuan dalam shooting baik dalam jarak jauh maupun jarak dekat. Kemampuan shooting dimiliki pemain karena tidak mungkin bagi pemain untuk mencetak gol tanpa memiliki kemampuan tersebut. Kemenangan sebuah tim ditentukan oleh kejelian seorang pemain untuk melihat peluang dan melakukan shooting kearah gawang secara tepat. Kemampuan shooting dapat didukung dengan awalan pada saat melakukan shooting dengan akurasi yang baik. Untuk itu supaya menjadi baik dalam menshooting dibutuhkan sebuah taktik yang mendukung salah satunya yaitu dengan melakukan permainan taktik. Supaya taktik yang mendukung untuk sebuah permainan atau pertandingan maka dibutuhkan sebuah latihan yang khusus. Dengan begitu atlet akan mendapatkan pengaruh tektik yang sistematis di dalam setiap masing-masing individu.

Yudiana, Subarjah, dan Juliantine (2010) menyatakan taktik adalah suatu siasat yang dirancang menjelang dan saat pertandingan berlangsung dan digunakan untuk usaha memenangkan pertandingan secara sportif dengan menggunakan teknik indidvidu, fisik, dan mental. Kesadaran taktik merupakan kunci dalam penampilan 


\section{Jurnal Ilmu Keolahragaan Volume II Nomor 1 April 2019 Faisal Idrus \\ Tersedia di: http://jurnal.untan.ac.id/index.php/jilo}

bermain, yang berupa untuk mengidentifikasi berbagai masalah dalam taktik (tactical problem) yang muncul selama permainan berlangsung dan meresponnya dengan cepat (Febrianta dan Sukoco, 2013). Dengan adanya taktik maka harus memiliki persiapan yang mendungkung untuk berprestasi. Persiapan yang matang harus mempunyai pola-pola yang baik. Persiapan taktik cendrung berhubungan dengan persiapan pola bertahan dan menyerang untuk memenuhi tujuan olahraga, seperti nilai untuk memperoleh kemenangan atau prestasi dalam pertandingan olahraga.

Menurut Yudiana, Subarjah, dan Juliantine (2010) dalam praktiknya secara garis besar taktik dapat dikelompokkan menjadi 2, yaitu sebagai berikut. (1) Taktik penyerangan adalah suatu siasat yang dijalankan oleh perorangan, kelompok maupun tim dengan maksud untuk mengusai pertandingan dan mendobrak pertahanan lawan dalam rangka untuk memenangkan pertandingan secara sportif. (2) Taktik pertahanan diartikan sebagai suatu siasat yang dijalankan oleh perorangan, kelompok maupun tim terhadap lawan dengan tujuan menahan serangan lawan agar tidak mengalami kelelahan dalam pertandingan. Permainan yang menerapkan taktik pertahanan mengharapkan dengan pasif agar penyerang melakukan kesalahan sendiri pada saat melakukan serangan.

Namun, banyak pemain yang memiliki kemampuan atau keterampilan dalam men shooting bola masih kurang baik. Biasanya pemain melakukan tendangan statis masih belum sempurna bagaimana lagi untuk permainan dinamis yang harus memiliki daya tahan yang kuat untuk menunjang melakukan semuanya. Untuk itu diperlukan sebuah strategi dan taktik yang mempuni semua itu. Penulis melihat bahwa di klub PSPI Pontianak masih belum memiliki kemampuan yang telah di kemukakan diatas. Atlet mereka masih belum melakukan penempatan posisi dan pengambilan keputusan yang benar, itu merupakan salah satu teknik didalam melakukan shooting yang berkualitas dan baik. Seperti yang telah dikemukankan oleh Rajidin (2014) bahwa teknik dan prinsip shooting merupakan kombinasi dan pemahaman pemain saat melakukan shooting yang harus diperhatikan dan diberikan latihan, karena hal ini merupakan komponen penting bagi seorang pemain agar mencetak gol dalam setiap situasi atau momentum pada setiap permainan dan pertandingan dimana terdapat kesempatan atau peluang didalamnya.

Metode teaching game for understanding merupakan sebuah bentuk latihan permainan taktik dimana pemain diharuskan untuk berfikir dan berusaha menyelesaikan sebuah bentuk permainan yang dirancang tersebuah. Untuk mendukung semua itu maka dibutuhkan sebuah latihan. Maka dari itu latihan yang cocok untuk mengembangkan taktik di dalam sebuah permainan sepakbola yaitu dengan menggunakan latihan Teaching Game for Understanding.

Pujianto mengatakan (2014) teaching game for understanding merupakan suatu pendekatan pembelajaran pendidikan jasmani untuk memperkenalkan bagaimana anak mengerti olahraga melalui konsep dasar bermain. TGfU (Teaching Game for Understanding) sebuah bentuk model pembelajaran permainan atau latihan dimana atlet bisa memahami cara melakukan permainan tersebut dan bagaimana menyelesaikannya di dalam sebuah bidang olahraga. Minimnya model latihan yang digunakan pelatih dalam latihan shooting sehingga hasilnya kurang maksimal dan permainannya pun mudah bosan dengan begitu adanya model latihan TGfU kemungkinan besar para atlet dengan menggunakan motode tersebut bisa meningkat rasa ingin berlatih yang tinggi dan termotivasi untuk melakukannya.

\section{METODE PENELITIAN Jenis Penelitian}

Bentuk penelitian yang digunakan dalam penelitian ini adalah penelitian 


\section{Jurnal Ilmu Keolahragaan Volume II Nomor 1 April 2019 Faisal Idrus \\ Tersedia di: http://jurnal.untan.ac.id/index.php/jilo}

eksperimen. Jenis penelitian eksperimen ini menggunakan pre-experimental design (nondesigns). Sugiyono (2013) dikatakan pre-experimental design, karena desain ini belum merupakan eksperimen sungguhsungguh, karena masih terdapat variabel luar yang ikut berpengaruh terhadap terbentuknya variabel dependen. Bentuk pre-experimental design, ada beberapa macam, yaitu: One-Shot Case Study, OneGroup Pretest-Posttest Design, dan IntactGroup Comparison. Menurut Prasetyo dan Jannah (2010) One-Group tre-test-post-test design, yaitu satu kelompok eksperimen diukur variabel dependennya (pre-test), kemudian diberikan stimulus, dan diukur kembali variabel dependennya (post-test), tanpa ada kelompok pembanding. Dari pendapat para ahli tersebut, peneliti menggunakan model One-Group PrettestPosttest Design.

$$
0_{1} \times 0_{2}
$$

Keterangan :

\section{Bagan 1. Pola Eksperimen}

$\mathrm{O}_{1} \quad=$ Pre-test (hasil observasi sebelum treatment)

$\mathrm{X}=$ Treatment (perlakuan)

$\mathrm{O}_{2} \quad=$ Post-test (hasil observasi sesudah treatment)

\section{Subyek Penelitian}

Populasi dalam penelitian ini adalah semua pemain Klub PSPI.

\section{Prosedur}

Penelitian ini melakukan pretest untuk mengetahui sejauh mana keterampilan menendang atau melakukan shooting bola pemain PSPI Pontianak disini diberikan untuk mendapatkan data awal sebelum diberikan perlakuan. Dengan menggunakan analisis Game Performance Assessment
Instrument (GPAI). Kemudian diberikan perlakuan selama 12 kali pertemuan. Perlakuan yang digunakan yaitu bentuk permainan judgment, bentuk permaian tersebut merupakan rancangan yang dibuat oleh peneliti sendiri. Setelah itu melakukan posttest untuk mengetahui sejauh mana keterampilan menendang atau menshooting bola setelah diberikan perlakuan.

\section{Alat Pengumpulan Data}

Alat pengumpulan data yang digunakan yaitu dengan menggunakan analisis Game Performance Assessemnt Instrument (GPAI). Sebagai berikut:

Tugas

Dalam kelompok, pastikan bahwa setiap anggota tim diobservasi. Pencatat perlu mengecek bahwa setiap orang telah melengkapi GPAI. Pelatih perlu mendiskusikan observasi tersebut dengan anggota tim dalam sesi pembentukan kelompok setelah permainan berlangsung.

Komponen-komponen penampilan bermain (kriteria untuk penilaian yang sesuai atau tidak sesuai)

1. Kriteria pengambilan posisi: pemain berusaha untuk mengoper pada teman satu tim yang berada diposisi yang baik, serangan yang sesuai (shooting, passing, dribbling).

2. Kriteria eksekusi perlakuan: bola mencapai target, terserah passing, shooting dan dribbling menggunakan kaki bagian apapun.

3. Hasil: usaha untuk membuat gol dengan 4 kali sentuhan, berkomunikasi dengan anggota tim (misal meminta bola).

4. Yang berhak mencetak gol hanyalah striker dengan waktu 3 menit.

5. Yang berhak mencatat penilaian dibawah ini yaitu pelatih atau asisten pelatih. 


\section{Jurnal Ilmu Keolahragaan Volume II Nomor 1 April 2019 \\ Faisal Idrus \\ Tersedia di: http://jurnal.untan.ac.id/index.php/jilo}

Table 1. Alat Pengumpulan Data

\begin{tabular}{|c|c|c|c|c|c|}
\hline \multirow{2}{*}{ Nama } & \multicolumn{2}{|c|}{$\begin{array}{c}\text { Pengambilan } \\
\text { Posisi }\end{array}$} & $\begin{array}{l}\text { Pengambilan } \\
\text { Keputusan }\end{array}$ & $\begin{array}{c}\text { Hasil men } \\
\text { Shooting }\end{array}$ & \multirow[t]{2}{*}{$\begin{array}{c}\text { Penilaian } \\
\text { keseluruhan }\end{array}$} \\
\hline & $\mathbf{S}$ & TS & $\mathbf{T} \quad \mathbf{T T}$ & TB & \\
\hline \multicolumn{6}{|l|}{$\begin{array}{l}\text { Memberikan } \\
\text { skor: }\end{array}$} \\
\hline Total: & & & & & \\
\hline
\end{tabular}

Kunci : $\mathrm{S}=$ sesuai, $\mathrm{TS}=$ tidak sesuai; atau $\mathrm{T}=$ tepat, $\mathrm{TT}=$ tidak tepat; atau $\mathrm{B}=$ berhasil, $\mathrm{TB}=$ tidak berhasil.

\section{HASIL PENELITIAN DAN PEMBAHSAN}

Berdasarkan data hasil penelitian, sebagian besar pemain mengalami peningkatan dalam tes tendangan shooting GPAI setelah diberikan perlakuan. Adapun tabel deskripsi hasil tes tendangan shooting GPAI sebagai berikut:

Tabel 2. Data Hasil Tes Tendangan Shooting

\begin{tabular}{ccccc}
\hline \multirow{2}{*}{ No. Atlit } & \multicolumn{3}{c}{ Hasil Shooting } \\
\cline { 2 - 5 } & \multicolumn{2}{c}{ Pretest } & \multicolumn{2}{c}{ Posttest } \\
\cline { 2 - 5 } & Shooting & GPAI & Shooting & GPAI \\
\hline $\mathbf{1}$ & 5 & 0,61 & 2 & 1,62 \\
\hline $\mathbf{3}$ & 1 & 0,15 & 2 & 1,27 \\
\hline $\mathbf{4}$ & 1 & 0,12 & 3 & 1,11 \\
\hline $\mathbf{5}$ & 3 & 0,25 & 2 & 1,55 \\
\hline $\mathbf{6}$ & 1 & 0,21 & 2 & 1,27 \\
\hline $\mathbf{7}$ & 1 & 0,19 & 4 & 1,27 \\
\hline $\mathbf{8}$ & 2 & 0,15 & 4 & 1,27 \\
\hline $\mathbf{9}$ & 1 & 0,19 & 3 & 1,33 \\
\hline $\mathbf{1 0}$ & 1 & 0,25 & 3 & 1,44 \\
\hline $\mathbf{1 1}$ & 2 & 0,16 & 3 & 1,58 \\
\hline $\mathbf{1 2}$ & 3 & 0,27 & 3 & 1,37 \\
\hline Mean & 1 & 0,58 & 3,08 & 1,11 \\
\hline Mininal & 1,83 & 0,23 & 2 & 1,62 \\
\hline Maxsimal & 1 & 0,12 & 6 & 1,18 \\
\hline SD & 5 & 0,21 & 1,16 &
\end{tabular}

Latihan judgment merupakan latihan yang paling efektif bagi atlit. Hal ini terbukti dari hasil statistik deskriptif posttest yang mana 12 anak dapat melakukan shooting ke sasaran dengan lebih baik, dibanding dengan hasil pretest. 


\section{Jurnal Ilmu Keolahragaan Volume II Nomor 1 April 2019 \\ Faisal Idrus \\ Tersedia di: http://jurnal.untan.ac.id/index.php/jilo}

\section{Gambar 1. Grafik Histogram Shooting}

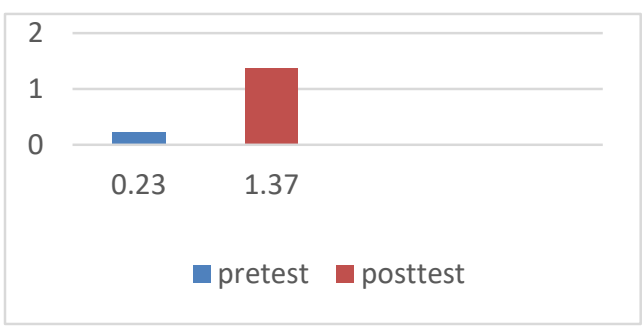
Gambar 2. Grafik Histrogram GPAI
Uji Prasyarat

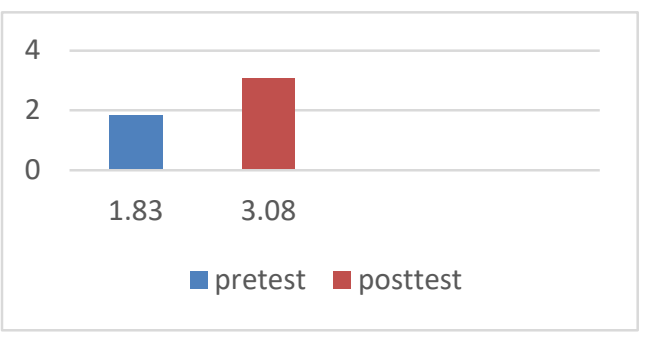

Sebelum menguji hipotesis, terlebih dahulu dilakukan pengujian prasyarat analisis. Adapun pengujian prasyataan analisis dilakukan dengan:

\section{Analisis Normalitas}

Uji normalitas data pada penelitian ini yang digunakan tes KolmogorovSmirnov. Hasil uji normalitas data yang dilakukan terhadap hasil tes awal dan tes akhir dapat dilihat pada table dibawah ini, dengan menggunakan SPSS versi 20 sebagai berikut:

Berdasarkan table di bawah hasil dari uji normalitas shooting nilai signifikansi pretest $0,001<0,05$, dapat disimpulkan berdistribusi tidak normal. Sedangkan nilai signifikansi data posttest $0,011<0,05$, dapat disimpulkan berdistribusi tidak normal. Untuk hasil data tabel uji normalitas GPAI nilai signifikansi pretest $0,002<0,05$, dapat disimpulkan berdistribusi tidak normal. Sedangkan nilai signifikansi posttest $0,062>0,05$, dapat disimpulkan berdistribusi normal.

Tabel 3. Hasil Uji Normalitas Shooting dan GPAI

\begin{tabular}{|l|l|c|c|c|c|c|}
\hline & \multicolumn{7}{|c|}{ Kolmogorov-Smirnov (a) } \\
\hline & \multicolumn{5}{|c|}{ Shooting } \\
\hline & statistik & Df & \multicolumn{1}{|c|}{ Sig. } & statistik & Df & Sig. \\
\hline Pretest &, 328 & 12 &, 001 &, 308 & 12 &, 002 \\
\hline Posttest &, 279 & 12 &, 011 &, 236 & 12 &, 062 \\
\hline
\end{tabular}

\section{Analisis Homogenitas}

Sebelum dilakukan analisis data perlu di uji distribusi homogenitasnya. Uji homogenitas data pada penelitian ini yang digunakan tes anova. Hasil uji homogenitas data yang dilakukan terhadap hasil tes awal dan tes akhir dapat dilihat pada tabel dibawah ini dengan menggunakan SPSS versi 20 sebagai berikut:

Berdasarkan Output SPSS data tabel di bawah diketahui hasil uji homogenitas shooting diketahui nilai signifikansi sepakbola adalah sebesar $0,581>0,05$, artinya data terhadap hasil menshooting sepakbola berdasarkan variabel pretest dan posttets terdapat varian yang sama.

Sedangkan untuk data tabel uji homogenitas GPAI diketahui nilai signifikansi variable Pengaruh Metode Teaching Game for Understanding (TGfU) adalah sebesar $0,087>0,05$, artinya data variabel Pengaruh Metode Teaching Game for Understanding (TGfU) berdasarkan variabel prettest dan posttest terdapat varian yang sama. 


\section{Jurnal Ilmu Keolahragaan Volume II Nomor 1 April 2019 Faisal Idrus \\ Tersedia di: http://jurnal.untan.ac.id/index.php/jilo}

\begin{tabular}{ccccc} 
Tabel 4. Hasil Uji Homogenitas \\
Shooting dan GPAI \\
$\begin{array}{c}\text { Levence } \\
\text { Statistik }\end{array}$ & df1 & df2 & Sig. \\
\hline Shooting & .314 & 1 & 22 & .581 \\
\hline GPAI & 3.209 & 1 & 22 & .087 \\
\hline
\end{tabular}

\section{Uji Hipotesis}

Uji hipotesis yaitu dengan menggunakan uji non parametrik. Tujuan uji Wilcoxon adalah alternative untuk uji $t$ data berpasangan (t-paired), dimana uji Wilxocon data harus dilakukan pengurutan (ranking) dan kemudian baru diproses. Hal ini berbeda dengan data pada uji $t$ paired yang bisa langsung diproses karena tipe data uji t paired yang interval/rasio. Hasil uji Wilcoxon antara pretest dan posttest dapat dilihat pada tabel dibawah ini dengan menggunakan SPSS 20 sebagai berikut:

Pada output SPSS data tabel di bawah hasil tabel shooting di atas didapat nilai Asymp. Sig. (2-tailed) 0,004 < 0,05 maka dapat disimpulkan bahwa " $\mathrm{H}_{\mathrm{a}}$ diterima". Artinya ada perbedaan antara hasil latihan TGfU terhadap kemampuan shooting sepakbola untuk pretest dan posttest, sehingga dapat disimpulkan bahwa "ada pengaruh metode Teaching Game for Understanding (TGfU) terhadap kemampuan shooting sepakbola".

Sedangakan output SPSS data hasil tabel GPAI didapat nilai Asym. Sig. (2tailed) $0,003<0,05$, maka dapat disimpulkan bahwa " $\mathrm{H}_{\mathrm{a}}$ diterima". Artinya ada perbedaan antara hasil latihan TGfU terhadap kemampuan shooting sepakbola untuk pretest dan posttest, sehingga dapat disimpulkan bahwa "ada pengaruh penggunaan metode Teaching Game for Understanding (TGfU) terhadap kemampuan shooting sepakbola".
Tabel 5. Hasil Test Statistik ${ }^{a}$ Wilxocon Shooting dan GPAI

\begin{tabular}{lll}
\hline & \multicolumn{2}{c}{ Hasil Wilcoxon } \\
\hline & & $\begin{array}{c}\text { Posttest- } \\
\text { Pretest }\end{array}$ \\
\hline \multirow{2}{*}{ Shooting } & $\mathrm{Z}$ & $-2.887^{\mathrm{b}}$ \\
\cline { 2 - 3 } & $\begin{array}{l}\text { Asymp.Sig.(2- } \\
\text { tailed) }\end{array}$ & .004 \\
\hline \multirow{2}{*}{ GPAI } & $\mathrm{Z}$ & $-2.981^{\mathrm{b}}$ \\
\cline { 2 - 3 } & $\begin{array}{l}\text { Asymp.Sig.(2- } \\
\text { tailed) }\end{array}$ & .003 \\
\hline
\end{tabular}

\section{Pembahasan}

Pada tahapan level I atlet baru mengenal proses latihan taktik dan mencobakan tetapi tidak ada kendala dalam tahapan level ini karena latihannya berisikan cara permainan yang biasa diterapkan pada latihan-latihan yang mereka dapat sebelumnya, jadi mereka terbiasa untuk melakukannya. Latihan level ini berfokuskan pada bagamana mereka bisa membuat goal sebanyak banyaknya. Sebelumnya mereka juga sudah diberikan contoh untuk melaksanakan perlakuan tahapan level ini.

Pada latihan tahapan level ke 2 atlit lebih difokus untuk melakukan shooting ke gawang dan sebelumnya meraka diberikan contoh cara melakukannya. Tahapan ini mereka juga tidak begitu kesulitan dalam melaksanakannya, karena perlakuan ini berfokuskan pada arahnya menuju gawang dengan dibantu beberapa atlit.

Kemudian pada latihan tahapan level ke 3 atlit lebih difokuskan pada latihan bermain cara bertahan supaya bola selalu berada pada satu timnya sendiri. Selanjutnya mereka diperuntunkan untuk saling bekerja sama dan saling mendukung utnuk mengontrol bola supaya tidak direbut oleh lawannya. Tahapan ini mereka agak kesulitan di dalam melakukkan perminan karena latihan ini selain diperlukan daya tahan yang kuat mereka di paksa untuk bagaimana cara meyelesiakan permaslahan yang mereka hadapi untuk mengelabuhi lawan.

Pada latihan tahapan level ke 4 atlit lebih difokuskan untuk menyelesaikan permainan dengan diberi waktu tertentu 


\section{Jurnal Ilmu Keolahragaan Volume II Nomor 1 April 2019 Faisal Idrus \\ Tersedia di: http://jurnal.untan.ac.id/index.php/jilo}

supaya mendapatkan kemenangan, bagi tim yang kalah akan mendapatkan hukuman. Selain itu mereka juga diperuntunkan untuk saling berkumunikasi setiap permainan yang mereka laksanankan. Mereka juga ditegaskan untuk melaksanakan permaian secara terbuka untuk menjauhi lawan. Pada tahapan ini mereka merasa kesulitan apa yang harus mereka perbuat karena mereka diperintahkan untuk melakukkan passing jauh.

Pada latihan tahapan level ke 5 berfokuskan untuk selalu berani dalam mengambil keputusan bergerak aktif di dalam segala ancaman dan mampu berduel. Disni mereka juga agak kesulitan untuk melaksanakannya karena pada tahapan level ini mereka dipusatkan pada latihan mengheading atau mencetak goal dalam kondisi atau ancaman dari lawan supaya menghasilkan sebuah goal. Dengan dilakukkan terus-menerus lambat laun mereka terbiasa untuk melakukan perlakuan yang peneliti berikan walau ada beberapa atlet yang masih kurang untuk melaksanakan perlakuan yang diberikan.

Dilihat dari proses latihan menggunakan metode TGfU dengan keterampilan menshooting bola dengan tepat dan memiliki level yang berbeda-beda serta bervariasi dapat meningkatkan keterampilan bermain taktik serta men shooting bola ke gawang, sehingga atlit merasa antusias dan termotivasi untuk melaksanakannya.

Penelitian ini bertujuan untuk mengetahui pengaruh metode teaching game for understanding (TGfU) terhadap kemampuan shooting sepakbola. Berdasarkan hasil data menunjukan rerata hasil kemampuan pretest shooting sebelum diberi perlakuan yaitu 1,83 . Nilai skor hasil test awal sebelum perlakuan nilai tertinngi yaitu 5 dan yang terendah yaitu 1 . Rerata skor akhir posttest shooting sesudah diberikan perlakuan yaitu 3,08 dengan hasil tes akhir tertinggi yaitu 6 dan nilai terendah yaitu 2.

Sedangkan untuk nilai rerata pretesr GPAI sebelum diberi perlakuan yaitu 0,23.
Nilai skor hasil test awal sebelum perlakuan nilai tertinggi 0,61 dan untuk nilai terendah sebelum diberi perlakuan yaitu 0,12 . Untuk rerata nilai posttest GPAI sesudah diberi perlakuan yaitu 1,37 dengan hasil test akhir nilai tertinggi yaitu 1,62 dan nilai terendah 1,11 . Dengan hasil yang didapat, bahwa ada peningkatan yang didapat sebelum dan sesudah perlakuan. Berdasarkan hasil uji hipotesis sudah dapat diketahui nilai signifikansi dari shooting 0,004 < 0,05 dan nilai signifikansi nilai dari GPAI $0,003<$ 0,05 sebagai pengaruh dari variabel indenpenden terhadap variabel dependen.

\section{KESIMPULAN DAN SARAN \\ Kesimpulan}

Berdasarkan hasil penelitian yang telah diperoleh maka dapat ditarik kesimpulan ada pengaruh positif dan signifikan. Pengaruh signifikan bentuk permainan judgment dengan mengikuti metode TGfU terhadap kemampuan shooting dalam permainan sepakbola.

\section{Saran}

Berdasarkan simpulan diatas, maka peneliti dapat mengungkapkan beberapa saran untuk dijadikan sebagai bahan pertimbangan, adapun saran-saran yang diutarakan sebagai berikut:

1. Dalam upaya meningkatkan kemampuan permainan taktik khususnya untuk pelatih harus memperhatikan komponen pengambilan posisi, pengambilan keputusan dan, melakukan shooting dengan baik atau kemampuan kognitif.

2. Berdasarkan keterbatasan dari penelitian di atas, peneliti menyarankan kepada peneliti yang sama agar memperhatikan juga kondisi motorik, emosi, maupun biologis sehingga data yang terkumpul lebih menyeluruh dan dapat memunculkan penelitian yang baru yang lebih inovatif, dan kreatif.

3. Penelitian ini dapat dilanjutkan ole peneliti lain dengan permasalahan yang lebih luas dengan jumlah sampel 


\section{Jurnal Ilmu Keolahragaan Volume II Nomor 1 April 2019 \\ Faisal Idrus \\ Tersedia di: http://jurnal.untan.ac.id/index.php/jilo}

yang lebih besar, sehingga dapat memberikan masukan kepada pelatih, pembina, maupun pemain guna meningkatkan prestasi cabang olahraga sepakbola.

\section{Daftar Pustaka}

Al-Hadiqie, Z.M. (2013). Menjadi Pemain Sepak Bola Profesional. Jakarta: Kata Pena.

Bianca, F. (2010). Seri Olahraga Anak Sepakbola. Jakarta: Perpustakaan Nasional: katalog dalam terbitan (KDT).

Dewi, C.C. dan Sitompul, H. (2016), Pengaruh Pemberian Umpan Balik dan Kemampuan Motorik Terhadap Hasil Belajar Shooting Siswa SMP Negeri Dikecamatan Langsa Kota. Jurnal Teknologi Pendidikan. 9 (1): 14-25.

Fadillah, R. (2009). Ayo, Bermain Sepakbola. Banten: Kenanga Pustaka Indonesia.

Febrianta, Y. dan Sukoco, P. (2013). Upaya Peningkatan Pembelajaran Permainan Bolabasket Melalui Metode Pendekatan Taktik Siswa
SMPN 2 Pandak Bantul. Jurnal Keolahragaan. 1 (2): 186-196.

Ferdinansyah dan Abitur. (2008). Sepak Bola. Jakarta: CV Utan Kayu Sejati.

Istofian, R.S. dan Amiq, F. (2016). Metode Drill Untuk Meningkatkan Teknik Menendang Bola (Shooting) Dalam Permainan Sepakbola. Jurnal Kepelatihan Olahraga. 1 (1): 105113.

Prasetyo, B dan Jannah, L.M. (2010). Metode Penelitian Kuantitatif. Jakarta: PT Rajagrafindo Perseda.

Pujianto, A. (2014). Persepsi Guru Pendidikan Jasmani Terhadap Model Teaching Game for Understanding (TGfU). Journal of Phsycal Education, Health and Sport. 1 (2): 80-85.

Rajidin. (2014). Model Latihan Shooting Ke Gawang Pada Mahasiwa UKM Sepak Bola IKIP-PGRI Pontianak. Jurnal Pendidikan Olahraga. 3 (2): 192-201

Sugiyono. (2013). Metode Penelitian Pendidikan. Bandung: Alfabeta.

Yudiana, Y. Subarjah, H. dan Juliantine, T. (2010). Dasar-Dasar Kepelatihan. Edisi 5. Universitas Terbuka. Jakart 